$12-20-2001$

\title{
Horses Damp the Spring in Their Step
}

Alan M. Wilson

The Royal Veterinary College, awilson@rvc.ac.uk

M. Polly McGuigan

The Royal Veterinary College

Anne Su

Cleveland Clinic Foundation

Antonie J. van den Bogert

Cleveland State University, a.vandenbogert@csuohio.edu

Follow this and additional works at: https://engagedscholarship.csuohio.edu/enme_facpub

Part of the Biomechanical Engineering Commons

How does access to this work benefit you? Let us know!

\section{Original Citation}

Wilson, A. M., McGuigan, M. P., Su, A., 2001, "Horses Damp the Spring in their Step," Nature, 414(6866) pp. 895-899.

This Article is brought to you for free and open access by the Mechanical Engineering Department at EngagedScholarship@CSU. It has been accepted for inclusion in Mechanical Engineering Faculty Publications by an authorized administrator of EngagedScholarship@CSU. For more information, please contact library.es@csuohio.edu. 


\title{
Horses damp the spring in their step
}

\author{
Alan M. Wilson*, M. Polly McGuigan*, Anne Su† \\ \& Anton J. van den Bogert + \\ * Department of Veterinary Basic Sciences, The Royal Veterinary College, Hatfield, \\ Herts AL9 7TA, UK \\ $\dagger$ Department of Biomedical Engineering, Cleveland Clinic Foundation, \\ 9500 Euclid Avenue, Cleveland, Ohio 44195, USA
}

The muscular work of galloping in horses is halved by storing and returning elastic strain energy in spring-like muscle-tendon units $^{1,2}$.These make the legs act like a child's pogo stick that is tuned to stretch and recoil at 2.5 strides per second. This mechanism is optimized by unique musculoskeletal adaptations: the digital flexor muscles have extremely short fibres and significant passive properties, whereas the tendons are very long and span several joints ${ }^{3,4}$. Length change occurs by a stretching of the spring-like digital flexor tendons rather than through energetically expensive length changes in the muscle ${ }^{5}$. Despite being apparently redundant for such a mechanism ${ }^{5}$, the muscle fibres in the digital flexors are well developed. Here we show that the mechanical arrangement of the elastic leg permits it to vibrate at a higher frequency of $30-40 \mathrm{~Hz}$ that could cause fatigue damage to tendon and bone. Furthermore, we show that the digital flexor muscles have minimal ability to contribute to or regulate significantly the $2.5-\mathrm{Hz}$ cycle of movement, but are ideally arranged to damp these high-frequency oscillations in the limb.

In a $500-\mathrm{kg}$ horse, about $1,000 \mathrm{~J}$ of elastic energy are stored in the digital flexor tendons and suspensory ligament (interosseus muscle) of each leg in each stride ${ }^{2,6}$. This is achieved by gravitational and 


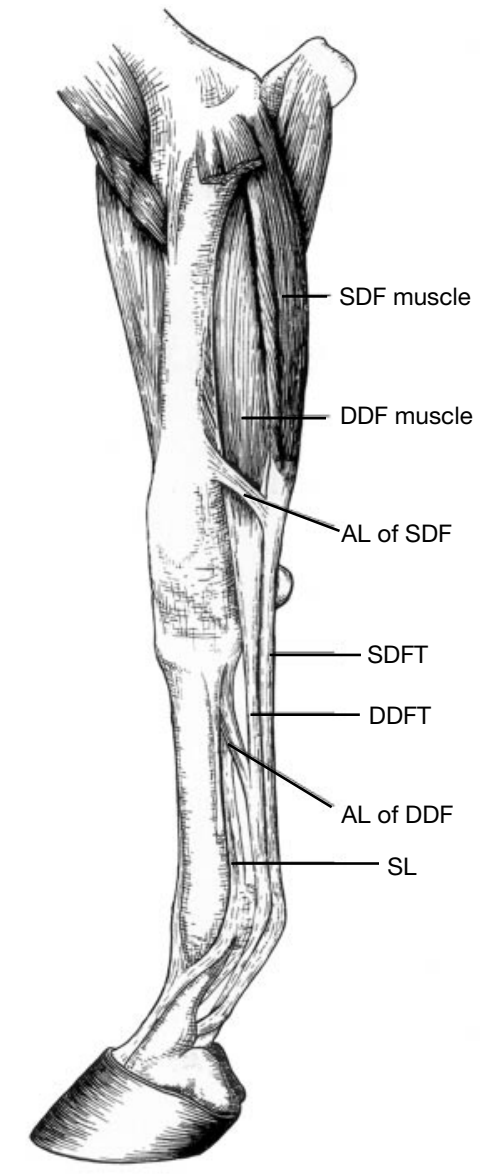

Figure 1 Equine distal forelimb (medial view) showing segments below the elbow, and the tendons and muscles that resist compression of the limb by the effect of gravitational and inertial forces during the stance phase of locomotion. This part of the limb is about $1 \mathrm{~m}$ long in a 450-kg thoroughbred racehorse. AL, accessory ligament; DDF, deep digital flexor; SDF, superficial digital flexor.

inertial forces that extend the metacarpophalangeal joint and stretch these collagenous structures (Fig. 1). Animals (including humans) that store elastic energy in their tendons have compliant tendons $s^{5}$ and minimize length change in the associated muscle ${ }^{7-9}$. The muscle instead preloads ${ }^{10,11}$ and/or powers the system by shortening at low tendon forces ${ }^{7}$. Further efficiency gains may be achieved by shortening or removing the muscle fibres, because the energetic cost of generating isometric force is a function of muscle fibre length over activated volume $e^{3-5}$. The endpoint of this optimization is shown in the completely collagenous interosseus muscle of the adult horse.

However, the equine forelimb superficial and deep digital flexor muscles remain well developed (mass 600-1,000 g), and 98\% (see Methods) of the physiological cross-sectional area comprises extremely short (superficial, 2-6 mm; deep, 6-17 mm) muscle fibres ${ }^{1,6,10,11}$. Similar short-fibred muscles exist in the hindlimb. Each muscle has a maximum isometric force of about 5,000 N $(n=5)$. The tendons are about $700 \mathrm{~mm}$ long and the muscles about $400 \mathrm{~mm}$ long. A peak tendon strain of $8-12 \%$ during locomotion $^{1,12,13}$ equates to a tendon elongation of $70 \mathrm{~mm}$ and, assuming similar aponeurosis strains, a muscle elongation of $40 \mathrm{~mm}$. Both muscles are protected from overextension by short $(50 \mathrm{~mm})$ and hence, when loaded, stiff accessory ligaments that link the tendon distal to the muscle belly to the bone, effectively acting as an additional parallel elastic element.

Assuming a change in sarcomere length of $35 \%$ and muscle force in excess of the long-fibred head isometric capacity $(230 \mathrm{~N})$, then

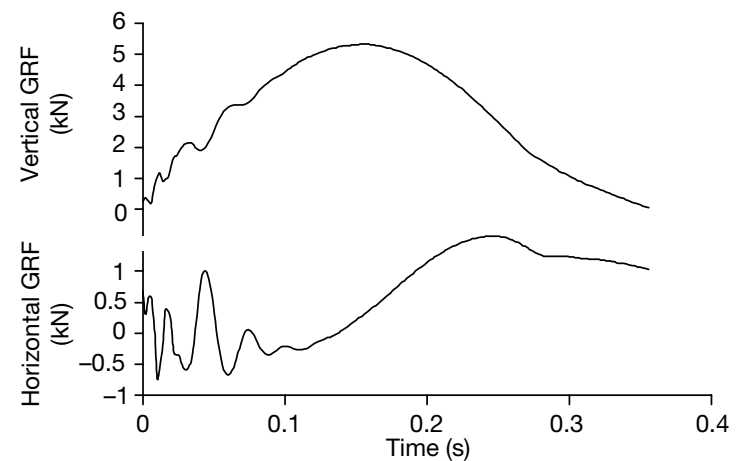

Figure 2 Plot of horizontal (in direction of locomotion) and vertical limb ground reaction force (GRF) against time for a 450-kg horse trotting at $3 \mathrm{~m} \mathrm{~s}^{-1}$ over a 6 -mm-thick polyester/rubber-matting-covered conveyor-belt force plate. The inflections in the curves during early stance are due to limb vibration excited by foot impact.

the superficial and deep digital flexor muscle contractile elements should change length by only $1-2 \mathrm{~mm}$ and $2-6 \mathrm{~mm}$, respectively. The long-fibred head appears sufficient to flex the digit during limb protraction, but the role of the short-fibred heads remains unclear. With potential contractile element length changes of 2 and $6 \mathrm{~mm}$ in a muscle tendon unit elongation of $60-80 \mathrm{~mm}$, the muscles appear inappropriate for tuning the leg spring ${ }^{10}$ or driving the spring system as in other energy-storing tendons ${ }^{7-9}$. It is possible, however, that the short fibres can, owing to lateral force transmission through the complex three-dimensional (3D) architecture of the muscle, achieve a length change greater than that predicted from fibrelength measurements ${ }^{14}$.

Hoof impact, slide and resonance lasts $20-30 \mathrm{~ms}$. Foot impact excites the equine limb to vibrate in a cranio-caudal direction at a frequency of $30-40 \mathrm{~Hz}$ (Fig. 2) ${ }^{15}$. The vibrations are similar on different surfaces (tarmac $35.9 \pm 1.2 \mathrm{~Hz}$; concrete $35.8 \pm 2.1 \mathrm{~Hz}$; rubber matting $34.9 \pm 1.2 \mathrm{~Hz} ; n=8$ ), and correspond to a muscle-tendon unit length change of about $2 \mathrm{~mm}$ (from joint angle changes) and an energy of 4-8 J. The vibrations are damped within $100 \mathrm{~ms}$ on hard surfaces and more quickly on soft surfaces. Similar frequency oscillations occur in the hindlimb and a simulation thereof ${ }^{16}$, but are damped within a cycle. Notably, $40-50-\mathrm{Hz}$ horizontal vibrations are present for about $100 \mathrm{~ms}$ after impact in accelerometer and kinematic data recorded from the human tibia during barefoot running ${ }^{17}$.

Excessive high-frequency vibration in the limb will cause fatigue damage in both bone ${ }^{18}$ and tendon ${ }^{19}$ by increasing the number of loading cycles and the loading rate experienced by the distal limb tissues. Musculoskeletal injuries are extremely common in athletic horses, and most of them occur in this spring system, which has been shown to fail through cyclical fatigue damage in as little as 10,000 strides of gallop ${ }^{20,21}$. A statistical correlation between highfrequency components in the ground reaction force and the development of tendonitis in racehorses has also been shown ${ }^{22}$.

Control and damping of vibration is an important design feature of manmade mechanical systems. Machines are usually designed to be rigid, but elastic deformation is an essential functional property of the equine limb and some innovative legged robots ${ }^{23}$. This elasticity and the multi-joint leg spring makes limb vibration inevitable, and it seems essential that this vibration is appropriately damped. The digital flexor muscles have extremely short fibres but a large physiological cross-sectional area. Muscles are good at absorbing energy ${ }^{24}$, so these short-fibred muscles appear ideally arranged for absorbing energy during high-frequency small displacement vibration.

One front leg from each of six horses killed at an abattoir was mounted in a hydraulic press at three different limb orientations representing impact through to mid-stance. The limbs vibrated for 


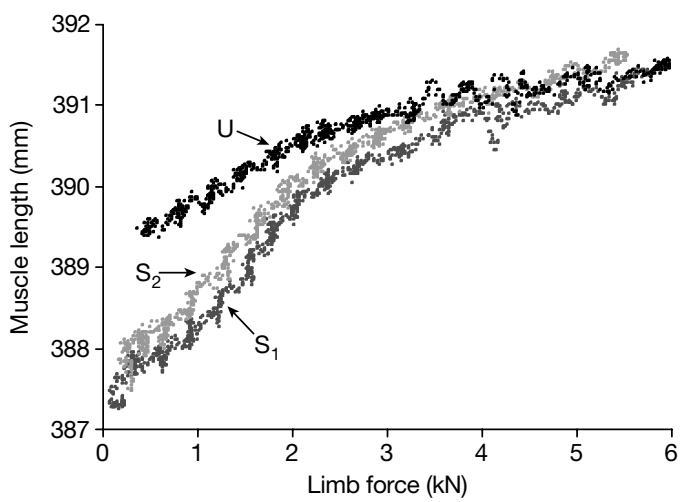

Figure 3 Relationship between limb force and muscle length for an equine superficial digital flexor muscle loaded in situ in the unstimulated state (U), and two sequential cycles with maximal electrical stimulation $\left(S_{1}, S_{2}\right)$. The difference between plots $U$ and $S_{1}, S_{2}$ represents the length change in the contracted muscle, and the difference between plots $S_{1}$ and $S_{2}$ represents the decline in contractile properties with repeated loading. Similar data were obtained for the deep digital flexor muscle.

$3-5$ cycles at $25-45 \mathrm{~Hz}$ when an impulse was applied to the carpal joint with a 1-kg hammer. Vibration frequency increased with limb force $(28 \mathrm{~Hz}$ at $1 \mathrm{kN}$ to $38 \mathrm{~Hz}$ at $4 \mathrm{kN})$ and was $4 \mathrm{~Hz}$ higher at impact orientation $\left(26.5^{\circ}\right.$ to vertical) than at mid-stance orientation. Another six legs were compressed up to $6 \mathrm{kN}$ (roughly gallop force) at mid-stance orientation over $5 \mathrm{~s}$, twice with and twice without electrical stimulation $(50 \mathrm{~Hz}, 60 \mathrm{~V})$ of the digital flexor muscles. It is unlikely that full muscle activation is achieved in this loading system (or during locomotion), but the length change would still be similar at low limb forces. Experiments were completed within $1 \mathrm{~h}$ of death, muscle temperature remained above $37^{\circ} \mathrm{C}$, and repeat plots were similar (Fig. 3).

At low limb forces, both muscles were $2-3 \mathrm{~mm}$ shorter when stimulated. The stimulated muscle lengthened more than the unstimulated muscle with increasing limb force (Fig. 3), absorbing energy in the limb force range at which the leg vibrations are damped (Fig. 2). The stimulated muscle lengthened more because the muscle was shorter at the start of loading, and when the isometric capacity of the contractile element was exceeded the muscle lengthened and the load was transferred to the parallel elastic element and the accessory ligament.

The accessory ligament is shorter $(50 \mathrm{~mm}$ compared with $300 \mathrm{~mm})$ and hence stiffer $\left(\mathrm{N} \mathrm{mm}^{-1}\right)$ than the muscle aponeurosis, so at high elongations most of the force will pass through it. This load transfer from the compliant muscle to the stiff accessory ligament accounts for the plateau of both the active and the passive muscle length curves above a limb force of $3 \mathrm{kN}$. The accessory ligament therefore limits muscle length change, keeping the muscle fibres at an appropriate length for developing active force and hence absorbing energy during oscillation.

Muscle stimulation had minimal effect on the relationship between limb force and limb length, showing that there is minimal change in limb stiffness and thus little potential for limb tuning through contraction of the digital flexor muscles. The limb spring may, however, be tuned by the muscles associated with the elbow and shoulder joints or those attaching the scapula to the trunk.

We created a numerical model of the system that reproduced published in vivo joint angles and tendon strains (see Methods). The model in the reference state (leg vertical, no muscle activation and tarmac ground surface) also reproduced similar low $(2.9 \mathrm{~Hz})$ and high $(57.5 \mathrm{~Hz})$ natural frequencies to in vivo and ex vivo data when loaded with a mass of $200 \mathrm{~kg}$, that is, half body mass (Fig. 4). Reducing vertical and horizontal surface stiffness by $500 \%$ from that representing tarmac $\left(k=5 \times 10^{5} \mathrm{Nm}^{-1}\right)$ to that representing

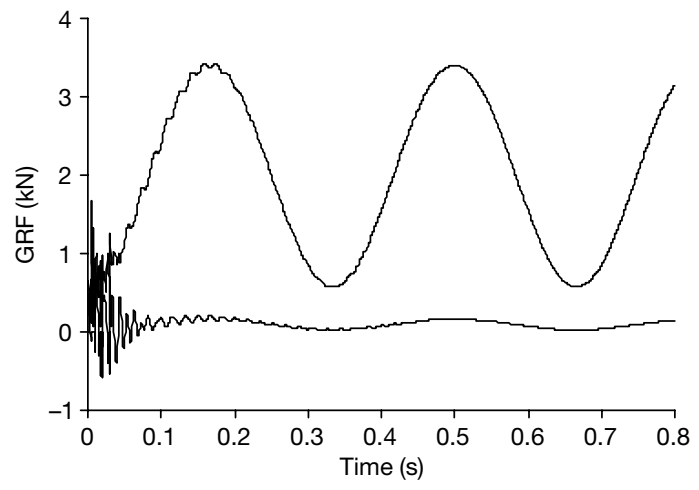

Figure 4 Vertical and horizontal ground reaction force (GRF) data produced from the equine limb model described in the text in the reference condition (leg vertical, no muscle activation, loading on tarmac). Top trace, vertical data; bottom trace, horizontal data. The initial oscillations are generated by the energy of the model being loaded by a mass of $200 \mathrm{~kg}$. Two frequencies of oscillation are apparent at 2.9 and $57.5 \mathrm{~Hz}$. There is no muscle stimulation in this case, and hence vibration damping is limited to the properties of the foot surface.

grass $\left(k=1 \times 10^{5} \mathrm{~N} \mathrm{~m}^{-1}\right)$ reduced the resonance frequencies by a much smaller amount to 2.7 and $34.1 \mathrm{~Hz}$. This is due to the reduction in stiffness of the overall system. An increase in damping coefficient increased damping of vibration but did not change the frequency. The model was loaded at limb orientations of foot impact $\left(26.5^{\circ}\right.$ to vertical) and mid-stance (vertical). At impact orientation, the resonance frequencies dropped from reference to 2.2 and $53.2 \mathrm{~Hz}$ because the limb is more compliant at this orientation.

In the model, muscle activation created muscle length changes greater than observed in the limb-loading experiment, had a damping effect on low-frequency oscillation (limb energy storage), but only a $3 \%$ tuning effect $(2.9$ to $3 \mathrm{~Hz})$, which is less than the surface effect. There was, however, no damping or tuning effect on high-frequency limb vibration. This is because Hill muscle models (almost universal in biomechanical modelling) fail to simulate high-frequency energy absorption ${ }^{24}$, because at high frequencies (and hence velocities) the contractile element remains almost isometric and the series elastic element absorbs most length change. Real muscles from a diverse range of animals (crayfish, frog, rat and rabbit), however, show a plateau or minimum in stiffness around $30-60 \mathrm{~Hz}$ (refs 24, 25). This effect is absent from muscle in rigor ${ }^{25}$. This suggests that the minimum is an inherent property of cross-bridge dynamics ${ }^{25}$, and we would predict that horse muscle will have similar frequency-dependent properties.

The cross-bridge model ${ }^{26,27}$ gives excellent simulations of the forces generated by live muscle fibres in response to small rapid length changes. We used the model to predict the energy absorbed by a cross-bridge when subjected to sinusoidal length changes of $0.5 \%$ at a range of frequencies. The assumption of constant displacement is reasonable because of the stiff accessory ligament in series with the muscle. There was a broad peak energy absorption of $15 \times 10^{-21} \mathrm{~J}$ per cross-bridge per cycle centred around $100 \mathrm{~Hz}$ (Fig. 5), which is similar to that reported for real muscle ${ }^{24,25}$. At $40 \mathrm{~Hz}$, a single cross-bridge would absorb $12 \times 10^{-21} \mathrm{~J}$ per cycle. Scaling-up for the digital flexor muscles $(1 \mathrm{~kg}$ of muscle containing $0.3 \mathrm{mM}$ myosin heads) gives a value of $2.5 \mathrm{~J}$ per cycle, which is sufficient to provide useful damping of limb vibration (energy 4$8 \mathrm{~J}$ ), but is tiny compared with the energetic cost of locomotion ${ }^{2}$. At stride frequency, the energy absorption was only $6 \times 10^{-21} \mathrm{~J}$ per cross-bridge.

Muscle fibres will therefore absorb more vibrational energy around $30-100 \mathrm{~Hz}$ than predicted by the Hill model, in which stiffness increases monotonically with frequency. Experimentally 


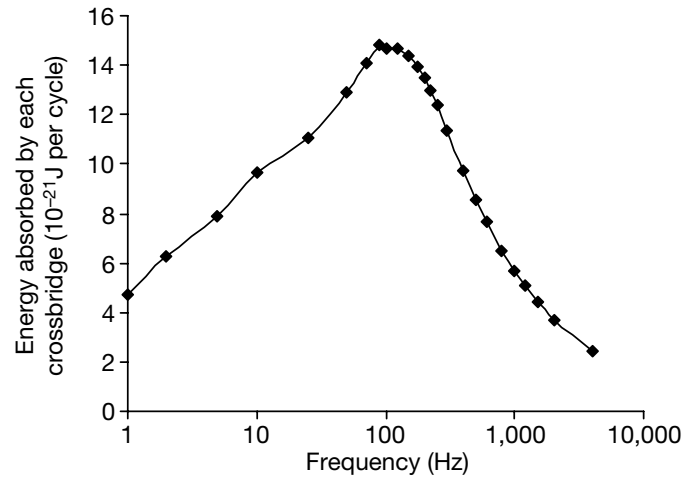

Figure 5 Plot of cycle work done on each cross-bridge in $10^{-21} \mathrm{~J}$ per cycle as a function of frequency $(\mathrm{Hz})$ during a sinusoidal length change of $0.5 \%$. These data were generated using the cross-bridge model of refs 26 and 27.

derived frequency-dependent muscle stiffness and phase data ${ }^{25}$ were used to predict the impulse response of a muscle-tendon-mass system geared to represent the limb vibration mechanism. We found resonance at $30 \mathrm{~Hz}$ and $88 \%$ damping in the first $100 \mathrm{~ms}$ of the impulse response. This simple model shows a similar response to that predicted from the cross-bridge simulations and supports the hypothesis that the muscles have appropriate architecture and properties to damp vibrations in the frequency range that occur in the equine limb.

In summary, the apparently functionless but well-developed digital flexor muscles in the horse appear to act as dampers of high-frequency limb vibration rather than to flex the digit or tune the leg spring. A cross-bridge muscle model can reproduce this muscle energy absorption and should be useful in recreating this high-frequency damping in musculoskeletal models of impact attenuation.

\section{Methods}

\section{In vivo measurements}

Eight horses were trotted over a forceplate (Kistler 9287BA) topped with either 6-mm-thick conveyor belt matting (a composite of polyester fibre and artificial rubber), bitumous roadstone (tarmac) or concrete. The frequency of leg vibration was determined from each plot of ground reaction force/time and averaged for six runs (three per forelimb) per horse and surface.

\section{Measurements of muscle architecture}

The superficial digital flexor muscle and the humeral (long-, intermediate- and shortfibred components separate), ulnar and radial heads of the deep digital flexor muscle were dissected free. We weighed each head and measured the fascial length (along the line of fibres between aponeuroses) at ten sites distributed across each muscle head. We calculated physiological cross-sectional area assuming a muscle density of $1.1 \mathrm{~g} \mathrm{~cm}^{-3}$, and maximum isometric force assuming a capacity of $30 \mathrm{~N} \mathrm{~cm}^{-2} 5$. No further correction for pennation angle or collagenous volume of the muscle was made.

\section{Ex vivo limb loading}

Forelimbs were cut perpendicular to the limb axis just proximal to the olecranon with the elbow at a mid-stance angle and a $13-\mathrm{mm}$ diameter hole drilled through the dista humerus and the elbow joint. The leg was mounted in a hydraulic jig through a flat plate with a central, hinged $12-\mathrm{mm}$ pin placed into the pre-drilled hole. The foot was placed on a force-measuring foot plate. We placed retroreflective markers over the centres of rotation of the elbow, carpal, metacarpophalangeal and distal interphalangeal joints. Retroreflective headed pins were inserted into the origin and muscle tendon junction of the deep and superficial digital flexor muscles, and data were recorded at $240 \mathrm{~Hz}$ (ProReflex, Qualisys). Wire electrodes (128-strand) were threaded through the deep and superficial digital flexor muscles, which were then wrapped in plastic film to prevent evaporative cooling.

\section{Musculoskeletal model}

A two-dimensional skeletal model of the equine forelimb was constructed, using five rigidbody segments connected by four ideal hinges. We used published segmental parameter (length, mass, moment of inertia and locations of the centre of mass ${ }^{28}$, and our model was conceptually similar to that in ref. 16. SD/FAST software (PTC) was used to obtain equations of motion. The model was stabilized by two muscle-tendon units, the superficial and deep digital flexors, two passive tendinous structures, the suspensory ligament and accessory ligament of the deep digital flexor, and a linear torsion spring, the palmar carpal ligament. Muscles were represented by a three-component Hill model based on that in ref. 29. Passive elastic elements were represented by a quadratic force-length relationship. Ground contact forces $F$ as a function of deformation $x$ were applied at two points on the hoof using a visco-elastic model $^{30}$.

$$
F=-k(x+b|x| \dot{x})
$$

where $k=5 \times 10^{5}$ or $1 \times 10^{5} \mathrm{~N} \mathrm{~m}^{-1}$, and $b=0.5 \mathrm{~s} \mathrm{~m}^{-1}$. Ground contact was modelled as a rigid hoof penetrating into a deformable surface. $x$ is the penetration depth. The model coefficients were chosen such that this model accounts for the combined deformation of surface and hoof. The stiffness coefficient $k$ for tarmac $\left(5 \times 10^{5} \mathrm{~N} \mathrm{~m}^{-1}\right)$ is based on a peak ground reaction force of $5,000 \mathrm{~N}$ producing a static deformation of $1 \mathrm{~cm}$; the equivalent deformation for turf $\left(k=1 \times 10^{5} \mathrm{~N} \mathrm{~m}^{-1}\right)$ is $5 \mathrm{~cm}$. The damping coefficient $b$ is based on ref. $30 ; b=0.5$ will produce a $50 \%$ increase in impact force when impact occurs at a speed of $1 \mathrm{~m} \mathrm{~s}^{-1}$, when compared with static deformation.

\section{Frequency domain model}

The limb is represented by a one-dimensional muscle-tendon-mass system, representing the mechanism of limb vibration. With external force as the input and mass displacement as the output of the system, the transfer function $H(f)$ of this system in the frequency domain is:

$$
H(f)=G \frac{k+s_{f}}{k s_{f}-4\left(k+s_{f}\right) \pi^{2} m f^{2}} \quad G=3.0, k=10^{6} \mathrm{Nm}^{-1}, m=10 \mathrm{~kg}
$$

where $f$ is the excitation frequency, $k$ is tendon stiffness, and $m$ is the oscillating mass, that is, the limb between the elbow and foot ${ }^{28}$. $G$ is the gear ratio for the limb, that is, the ratio between mass displacement and change in musculotendon length, derived from moment arms and bone lengths. The frequency-dependent stiffness $s_{\mathrm{f}}$ of the muscle, represented as a complex number with magnitude and phase, was taken from ref. 25 and scaled to a maximal force of 5,000 $\mathrm{N}$ and a fibre length of $5 \mathrm{~mm}$. Four such muscle-tendon units were assumed to account for individual heads and accessory ligaments. Complex stiffness is the ratio between force and displacement when both are sinusoidal signals $e^{2 \pi i t}$ in the complex domain, where $t$ is time and $i$ is $\sqrt{-1}$. Stiffness is a complex number $S e^{i \phi}$ where $\phi$ is the phase difference between force and displacement and $S$ is the amplitude ratio between force and displacement. The impulse response of the system was obtained by inverse Fourier transform of $H(f)$.

Received 1 March; accepted 12 October 2001

1. Dimery, N. J., Alexander, R. McN. \& Ker, R. F. Elastic extension of leg tendons in the locomotion of horses (Equus caballus). J. Zool. 210, 415-425 (1986).

2. Minetti, A. E., Ardigo, L. P., Reinach, E. \& Saibene, F. The relationship between mechanical work and energy expenditure of locomotion in horses. J. Exp. Biol. 202, 2329-2338 (1999).

3. Alexander, R. McN. \& Bennet-Clark, H. C. Storage of elastic strain energy in muscle and other tissues. Nature 265, 114-117 (1977).

4. Alexander, R. McN. Elastic Mechanisms in Animal Movement (Cambridge Univ. Press, Cambridge, 1988).

5. Biewener, A. A. \& Roberts, T. J. Muscle and tendon contributions to force, work and elastic energy savings: a comparative perspective. Exercise Sport Sci. Rev. 28, 99-107 (2000).

6. Biewener, A. A. Muscle-tendon stresses and elastic energy storage during locomotion in the horse. Comp. Biochem. Physiol. B 120, 73-87 (1998).

7. Biewener, A. A., Konieczynski, D. D. \& Baudinette, R. V. In vivo muscle force-length behaviour during steady state hopping in tammar wallabies. J. Exp. Biol. 201, 1681-1694 (1998).

8. Hof, A. L. In vivo measurement of the series elasticity release curve of human triceps surae muscle. J. Biomech. 31, 793-800 (1998).

9. Kurokawa, S., Fukunaga, T. \& Fukashiro, S. Behaviour of fascicles and tendinous structures of human gastrocnemius during vertical jumping. J. Appl. Physiol 90, 1349-1358 (2001).

10. Grandage, J. Penniform muscles of the horses forelimb. J. Anat. Abstr. 132, 318 (1981).

11. Hermanson, J. W. \& Cobb, M. A. Four forearm flexor muscles of the horse, Equus caballus: anatomy and histochemistry. J. Morphol. 212, 269-280 (1992).

12. Stephens, P. R., Nunamaker, D. M. \& Butterweck, D. M. Application of a Hall effect transducer for the measurement of tendon strains in horses. Am. J. Vet. Res. 50, 1089-1095 (1989).

13. Herrick, W. C., Kingsbury, H. B. \& Lou, D. Y. S. A study of the normal range of strain, strain rate and stiffness of tendon. J. Biomed. Mat. Res. 12, 877-894 (1978).

14. Bogert, A. J., van den Gerritsen, K. G. M. \& Cole, G. K. Human muscle modeling from a user's perspective. J. Electromyog. Kinesiol. 8, 119-124 (1998).

15. van Weeren, P. R., van den Bogert, A. J., Back, W., Bruin, G. \& Barneveld, A. Kinematics of the standardbred trotter measured at $6,7,8$ and $9 \mathrm{~ms}^{-1}$ on a treadmill after 5 months of prerace training. Acta Anat. 146, 154-161 (1993).

16. van den Bogert, A. J. \& Schamhardt, H. C. Multi-body modelling and simulation of animal locomotion. Acta Anat. 146, 95-102 (1993).

17. Lake, M. J., Coyles, V. R. \& Lees, A. High frequency characteristics of the lower limb during running. Proc. 18th Congr. Int. Soc. Biomech. (eds Müller, R., Gerber, H. \& Stacoff, A.) 200-201 (Laboratory for Biomechanics, ETH Zurich, 2001).

18. Carter, D. R. Mechanical loading histories and cortical bone remodeling. Calcif. Tissue Int. 36(Suppl.), 19-24 (1984).

19. Wang, X. T., Ker, R. F. \& Alexander, R. McN. Fatigue rupture of wallaby tail tendons. J. Exp. Biol. 198, 847-852 (1995).

20. Cheney, J. A., Liou, S. Y. \& Wheat, J. D. Cannon bone fracture in the thoroughbred racehorse. Med. Bio. Eng. 11, 613-620 (1973). 


\begin{abstract}
21. Nunamaker, D. M., Butterweck, D. M. \& Provost, M. T. Fatigue fractures in thoroughbred racehorses: relationships with age, peak bone strain, and training. J. Orthop. Res. 8, 604-611 (1990).

22. Dow, S. M., Leendertz, J. A., Silver, I. A. \& Goodship, A. E. Identification of subclinical tendon injury from ground reaction force analysis. Equine Vet. J. 23, 266-272 (1991).

23. Pratt, G. A. et al. Stiffness isn't everything. Proc. 4th Int. Symp. Experimental Robotics, ISER, Stanford, California 173-178 (1995).

24. Ettema, G. J. C. \& Huijing, P. A. Frequency response of rat gastrocnemius medialis in small amplitude vibrations. J. Biomech. 27, 1015-1022 (1994).

25. Kawai, M. \& Brandt, P. W. Sinusoidal analysis: A high resolution method for correlating biochemical reactions with physiological processes in the activated skeletal muscles of rabbit, frog and crayfish. J. Muscle Res. Cell. Motil. 1, 279-303 (1980).

26. Piazzesi, G. \& Lombardi, V. A cross-bridge model that is able to explain mechanical and energetic properties of shortening muscle. Biophys J. 68, 1966-1979 (1995).

27. Piazzesi, G. \& Lombardi, V. Simulation of the rapid regeneration of the actin-myosin working stroke with a tight coupling model of muscle contraction. J. Muscle Res. Cell. Motil. 17, 45-53 (1996).

28. van den Bogert, A. J. Computer Simulation of Locomotion in the Horse. Thesis, Univ. Utrecht, The Netherlands (1989).

29. van Soest, A. J. \& Bobbert, M. F. The contribution of muscle properties in the control of explosive movements. Biol. Cybern. 69, 195-204 (1993).

30. Gerritsen, K. G. M., van den Bogert, A. J. \& Nigg, B. M. Direct dynamics simulation of the impact phase in heel-toe running. J. Biomech. 28, 661-668 (1995).
\end{abstract}

\title{
Acknowledgements
}

We acknowledge the assistance of R. C. Woledge in carrying out the cross-bridge model calculations and thank him for comments on the manuscript. We thank the Horserace Betting Levy Board, London, for funding this work. 